\title{
Self- Spirituality and its Advantageous Impact for Positive Counselling Attitudes among Youths
}

\author{
Idowu Grace Tanimoonwo ${ }^{1}$; Hassan, Siti Aishah²; Azimi, Hamzah ${ }^{3}$; Baba, Maznah ${ }^{4}$
}

Universiti Putra Malaysia, Faculty of Educational Studies, Department of Counsellor Education and Counselling Psychology,

Email: tannymelord@gmail.com

Universiti Putra Malaysia, Faculty of Educational Studies, Department of Counsellor Education and Counselling Psychology,

siti_aishahh@upm.edu.my

Universiti Putra Malaysia, Faculty of Educational Studies, Department of Counsellor Education and Counselling Psychology,

azimihamzah49@gmail.com

Universiti Putra Malaysia, Faculty of Educational Studies, Department of Counsellor Education and Counselling Psychology,

mazb@putra.upm.edu.my

\begin{abstract}
This paper presents the influences of self-spirituality for prosperous Counselling attitudes among youths with particular focus on Nigerian students in Malaysian Universities, towards becoming positive agents of change in the society. The research paper analyses ways in which self-spirituality can be applied independently as a Counselling means to achieve positive attitudes among these university students. The Null hypothesis stated that there are no significant and direct relationships between self-spirituality and counselling attitudes. To carry out the research, two instruments were combined in a quantitative survey involving 394 students that were systematically drawn from ten randomly selected universities in Malaysia. The results of the data analysis indicate the fact that self-spirituality has a positive impact on counselling attitudes with $(\boldsymbol{\beta}=0.212$ and $p$ value $=0.002)$. The null hypothesis was therefore rejected. The analysis ends with a discussion that provides recommendations that can be adopted to ensure success of the self-spirituality use in counselling. The paper suggested with remarkable conclusion that since spirituality plays such an important role in every society, there should be more nurturing of it in the society while the Guidance Counsellors work towards directing the young people on the right path of God.
\end{abstract}

Key Words: Self-Spirituality, Counselling Attitudes, Challenges for youths, Nigerian students

\section{Academic Discipline and Sub-Disciplines}

Psychology

\section{SUBJECT CLASSIFICATION}

Guidance and Counselling Classification

\section{TYPE (METHOD/APPROACH)}

Quantitative research method with Multistage Cluster Sampling Technique

\section{INTRODUCTION}

The spiritual dimension of everything that the family does to be a family is often referred to as family spirituality. Today, most youths encounter certain challenges such as lack of self-confidence and low self-esteem leading to drug abuse, sexuality confusion and ambiguity concerning moral issues on what is right and what is wrong, crime and violence as a result of the negative impact of the electronic media e.g. X-rated movies, cybersex to mention but a few. These often require consultation with Guidance Counsellors and older family members to seek meaning to the unknown with an effort to have self-value, high self-esteem and positive attitudes.

Previous research has focused on schemes of initiating counselling through the professional caregiver. In this case, the caregiver is the Guidance Counsellor trained to listen and respond to social implications which affects the youth. However, while this approach is still applicable in many clinical settings as approved by American Psychology Association, some special cases are fragile and require the direct involvement of family members. Further still, most family members are not responsive enough to provide subsequent care if they are not intrinsically involved with the youth's life. For this reason, there is a general calling on self- spirituality for positive counseling attitudes among the Nigerian students in Malaysian universities.

Self-spirituality for the purpose of this study refers to the close relationship between the inner-soul of one's personality, beliefs and practices surrounding it because spirituality represents a necessary essence of life that energizes both thought 
and actions of human beings (Taylor, 2007). Similarly, counselling attitudes here focus on the attitude of the Nigerian students in seeking professional psychological help and social support in Malaysia.

The calling specifies the direct commitment of family members morally and psychologically and spiritually to rehabilitate the youth victim. Most of these deliberations are conducted by use of the responsive dialogues, prayer initiatives and fellowship programs. There is a close interrelation between spirituality and counseling. A person's spirit is often considered a motivation force of once individual actions and thoughts. The process of motivating the force of one's individual actions is considered a motivating force and is appropriately represented in all actions. Spirituality involves a close relationship between the inner-soul of one's personality, beliefs and practices surrounding it. The individual engages in self-exploration of his/ her religious beliefs with intent to increase understanding, sensitivity, and acceptance of his/her system. Demonstrating sensitivity acceptance of a variety of spiritual and religious expressions forms the integral concern of Counsellors. For this reason, a competent Guidance Counsellor has in mind several factors.

Firstly, the spiritual dimension of a person is an essential part of the youth who is seeking for the meaning of life. Secondly, the spiritual care of a person is a critical aspect that should be handled with outmost attention. Thirdly, the Guidance Counsellor should offer diversity and inclusivity on pastoral services and other communal initiatives. These diversities include race, ethnicity, sexual orientation, disability, age, and gender. Also, public advocacy related to spiritual values and social justice concerns are prompted on behalf of an individual.

Spiritual counseling also influences the nature of mental health of the youth. Turner (2004) constructs complex health relationship between two primary variables, mental health in respect to anxiety and depression and spirituality; that is, spiritual well-being and religious coping styles. This approach is seconded by Wolf (2001) who argues that, there is a complex relationship between spirituality and aspect of physical health. Therefore, this paper will examine in detail the philosophical approach to integrating spirituality and clinical work.

\section{PRESENT DAY CHALLENGES FOR YOUTHS}

\section{Lack of Self-confidence and low Self-esteem}

This is topmost on the list of challenges facing the youths today. Lack of self-confidence and self-esteem is a distinct condition of the mind. The minded nature of the individuals with low self-esteem often makes them have pre-conceived ideas against other individuals, a factor considered to increase the risk of misconception among them towards others in the society. Such experiences make them have preconceived negative perception as they feel comprising of the minority group in the society.

Individuals with low self-confidence and self-esteem are described as criminally minded people and bullies. Gold (2010) argues that when people with low-self-esteem are described in this scope, bad behaviors will naturally affect them as they will attempt to affiliate to a certain personality. Low self-confidence and self-esteem create feelings of social exclusion and the individual may adapt to social violence as refuge point. For this reason, it is coherent to consider the characteristics of low self-esteem that leads to an impaired lifestyle. On the other hand, a higher self-esteem may be equally problematic and this can lead to a poor performance since such an individual will naturally consider himself or herself effective. Therefore, providing spiritual counseling to youths with low self-esteem provides them with opportunities to realize their personality and that of other people; as it is important in developing one's own character. Oftentimes, it is the lack of selfconfidence that pushes youths to the next challenge on this list which is Drug Abuse.

\section{Drug Abuse}

It is highly appreciable that the field of addiction can both be historically and currently viewed as one of the key fields of counseling. The field is often open to integration into spirituality and counseling (Frame, 2003). The history of the merger of drug abuse, spirituality, and counseling in addiction dates back to alcoholism/addiction that was viewed through religious perspectives as being morally wrong. Religious perspectives considered addicts as people who are morally weak and lacking in willpower (Sink, 2008).

Drug addiction has been a contested debate in most religion-based releases. Analysis of different religions shows that drug addiction such as alcoholism has religious roots. The difference between the religious inclination of addiction and the current perspectives arise from the variance in the severity and incidences of drug abuse. Unlike the past, the current drug consumption rates are concerned in promoting hedonism. Methamphetamine, Heroin, Cocaine, and Ecstasy are structurally made to alleviate the mind of the user and give him a false feeling of joy and satisfaction (Ling, 2006).

Drug addiction is such a prevalent problem in youths. For this reason, Christian based counseling invites a feeling of hope and displacement from the drug. For instance, self-spiritually provides a framework for positive counseling attitudes in youths of today. The family offers fellowship and group support programs addressing the spiritual issues concerning integrity, identity, and inner life and interdependence (Kvarfordt, 2009). These steps promote spiritual awakening and prepare individuals and family members to practice principles of abstinence from drugs. In fact, Meier (2005) believes that the connection with a higher power through prayer and meditation facilitates the reflection of abstinence from drugs. Additionally, the serenity prayer at the heart influences the development of recovery moments and this is helpful to individual facing difficult circumstances (Jankowski 2009). 


\section{Negative Impact of Electronic Media}

Recently, there have been subsequent debates investigating the impact of electronic media, more so social media in creating social rifts. As technology grows, its negative impacts are fast reaching out to the people. People are more attached and engaged to their devices than ever before. As such, social ties have been broken paving the way for increased interests in electronic entertainment. Consequences range in all manners. Firstly, electronic media is primarily responsible in creating of sense of disconnection from ethical norms. Secondly, electronic media is primarily responsible for decreasing productivity. Thirdly, electronic media invades social privacy but increases loneliness. An individual does not concentrate in building one relationship, but multiple relationships, which are shallow and unproductive. For these reasons, there has been an increased impact of negative social media.

The primary concern of this research assesses the alienation of youths from the mainstream society and the way the concept of self-spirituality can act decisively in minimizing the rifts. As noted, there have been impacts of electronic media in creating divergent lifestyles amongst youth. The description has also identified the issue of loneliness as a justifying factor why people are engaged in social media. Following this conclusion, self-spirituality provides alternatives at which the youth is collectively engaged. Spirituality ensures that counseling attributes are engaged at various levels of social communication. More to these factors is the application of communication in apprehending a feeling of emptiness. Spirituality not only communicates to the individual inner soul, but also provides an authentic social affiliation one that justifies a given sense of social commitment. With self-spirituality, the youth does not feel alienated from the society; thus, he or she has more time to contribute positively to the society.

One of the negative impacts of electronic media is the promotion of crimes and violence among youths. For example youths who are addicted to playing video games may unconsciously start liking the killing of animals and human beings, use of drug substances, sexual exploitation and violence towards women, as well as racial, sexual, and gender discrimination. The games they play may also promote the use of vulgar language, obscenities, and explicit acts. These are some of the negative impacts that are being promoted by the electronic media that could lead to real crime and violence.

\section{Crime and Violence}

All over the world, there has been increased youth involvement in crimes; organized crime is appealing to many youths especially to those in college. Sandoz (2006) argues that the presence of complicated economic lifestyle is primarily responsible for decreasing relationship between youth and their parents. Increased amount of diversity amongst youth, seconded by drugs usage and low perceptions are primarily responsible in scheduling a culture of violence and social irresponsibility (Meier, 2005).

Crime and violence are lucrative strategies of achieving power and fast money. However, complicated family relationships are primarily responsible for the increased number of crime rates. For example, children with poor parental upkeep often feel isolated and neglected in the society. Such feeling predisposes them to engaging in criminal acts to counter their feeling of rejection and hopelessness (Gold, 2010).

Therefore, self-spiritual commitment seems like a desirable strategy that schedules cultural appropriateness. Briggs and Dixon (2013) found out that the primary cause of crime and violence is idleness and perceptions conflicts. Youths have traditionally felt abandoned by the society and crime or violence is the only way to respond to these issues. Further to this, the youth have traditionally engaged in crime as the only means to earn some sought of lifestyle. Family commitments towards engaging the youths in the society are geared towards realizing the impacts of the youth to the society.

Gold (2010) is compelled by the decision that religious commitments enable the youths to feel integrated collectively into the society. The youth wants to feel the society is concerned about their welfare. Lack of spiritual commitment on the other hand acts as a nullification of ethical principles. Additionally, spiritual commitment specifies what is required of the youth in relation to serving the society. This includes, social commitment in expanding the word or providing charity or philanthropic. Through this, the youth will feel like part of the social group.

Violence is complexity of attitudes and agendas geared to inflict harm to others. Youth will naturally engage in violence for their desire to prove triumphant and accomplish a given set of social goals. For this reason, violence acts as a communication channel that the youth want to express some factors. However, humanity is not based on malice or violence but on principles of decorum and benevolence. The youth only applies violence based on natural law theory and not utilitarianism (Frame, 2003). Issues associated with remorse remains to be an integral concern in violence initiatives. In fact, violence occurs in a spiral sequence that absorbs the youth deeper and deeper inside the violence.

However, Ciarrochi (2002) argues spirituality provides a collective healing formula that distances one from violence. Family spiritual commitment will keep the youth absorbed, engaged and principled for peace, and these are not stipulation of violence. Morally, spiritual commitment engages the youth in light with righteousness. Gockel (2004) specifies that human beings are in service for others, and this involves exit of violent activities. Furthermore, The youth will naturally feel violent as evil factor that is controlled by satanic attributes of malice and revenge. In summary, self- spiritual commitment is vital in uninstalling violence related tendencies. 


\section{Identity Crises}

In addition, there has been a strong influence on self-scrutiny and perception. This explains why more and more youths are gradually getting engaged in issues that are related to immorality, sexual transgression, same-sex partnership, ambiguity of personality to mention a few. This confusion is primarily responsible in scheduling cultures of hatred towards reality. Personality attitudes also form a central concern. Wolf and Stevens (2001) jointly argued that, these identity crises augment the increased commitment of the youth to sexual immorality, drugs or violence. As a result, there has been a general increase in rebellious attitudes. Moral issues on what is right or wrong form the nucleus of most debates.

Identity crises are a central concern of most religious debates. In fact, counseling seeks to examine the role of internal personality conflicts in increased self-rejection attitudes. However, in relation to this study, spirituality plays a critical role in eradicating personal frustration. Family spiritual commitment is not only concerned with the individual contribution towards fellowship requirements, but also seeks to investigate the individual lifestyles of the youth.

\section{Research Methods and Procedures}

To account for some possible complications that may occur throughout the research, like apathy of respondents, incomplete questionnaire, homogeneity of respondents and also to allow for non-response, the sample size was increased so the total number of distributed questionnaires was 500 and the collected questionnaires was 422 . After removing the incomplete questionnaires (106) 394 samples of both male and female, systematically drawn from the population of Nigerian students in ten different universities in Malaysia, were considered for data analysis.

\section{Type and Source of Data:}

The source of the data for this study was the primary data, freshly collected by administering self-completed questionnaires on the students one-on-one. This is because the secondary data relating to the variables of interest may not exist in the form conceptualized in this research. Moreover, since the latent variables of interest will be captured by a number of items via a combination of two established scales, it is only reasonable that the source of data collected should be primary.

\section{Instrumentation}

The two instruments combined in the self-administered questionnaire used to investigate this study are:

1. Self-Spirituality Personality Inventory (SSPI)

2. Attitude towards seeking Professional Psychological Help (ATSPPH)

Self- Spirituality Personality Inventory (SSPI): is a 5 -item measure based on the existing Universal Religious Personality Inventory (URPI) with 99 items developed by Azimi et al., (2012) which is considered too long for the practical purpose of capturing the only dimension of self-spirituality in this study. The five items selected from the URPI were selected to represent the most salient proposed dimension of self-spirituality and are considered to be the most relevant ones out of the 99 items in the long form for this aspect.

The main purpose of developing the SSPI was to determine whether the measure would be significant based on selfspirituality alone and to provide items that are pertinent and relevant to both Christianity and Islam, the two religions under focus in this study. Also it provides an opportunity to get evidence of this scale's validity and reliability. Although the original scale was 99 items long and the measure itself is a religiosity scale; yet because spirituality and religiosity are interwoven and sometimes used interchangeably according to (Ironson et al., (2002); Woods, \& Ironson, (1999); Koenig et al,. 1997); therefore it made it possible for some items under religiosity to be relevant for use in spirituality issues and viceversa as it were in this case. Craigie (1999) provided a rational for this interwoven nature of spirituality and religiosity when spirituality was defined as the inner dimension of all religious traditions that enhances an inter-religious view; hence these five selected items are relevant to self-spirituality because they directly measure the self-transcendence of the participants in this study.

\section{Attitudes toward Seeking Professional Psychological Help (ATSPPH- SF)}

Attitude toward Seeking Professional Psychological Help Scale (Fischer \& Farina, 1995) is one standardized psychometric instrument designed to measure the mental health treatment attitudes and also to assess the dimension of individual's attitudes toward seeking professional help. It is a modernized short form (ATSPPH-SF) consisting of only 10 items. The longer version, consisting of 29 items was developed by Fischer and Turner (1970). The counselling attitude in this study was operationally defined through the respondents' scores obtained through the 10 relevant questions on counselling attitudes, from the ATSPPH instrument. With it, Fischer and Farina (1995) identified four dimensions of counselling attitudes namely: recognition of need for psychological help, stigma tolerance, interpersonal openness and confidence in helpers. High score indicates positive counselling attitudes while low score implies negative counselling attitudes.

\section{Results}

The hypothesis proposed that there is no significant and direct relationship between spirituality and counselling attitudes. The results of this data analysis indicate the fact that spirituality has a positive impact on counselling attitudes with $(\boldsymbol{\beta}$ $=0.212$ and $p$ value $=0.002$ ) in table 1 . 
This is also comparable to other studies and it is consistent with existing literature on spirituality like Kim and Diaz, (2012) found that spirituality significantly influenced the quality of life and well-being of the Asian immigrants. The findings of Romero et al, (2005) buttressed this, with the report that spirituality was one of the unique predictors of less mood disturbance and better quality of life. Salsman et al, (2005) suggests that spirituality and religiousness are important predictors of behaviour adjustment. More-over, observation from responses on the demographic data on religion in the survey revealed that most of the respondents were either Christians or Muslims except for $0.8 \%$ who declared for other religions apart from the two popular ones. In summary, subsequent to this finding, the null hypothesis is rejected because the results of the study showed that it is statistically significant.

Table 1: Testing the Hypothesis

\begin{tabular}{|l|l|l|l|l|}
\hline \multicolumn{1}{|c|}{ Hypothesis } & Path & $\beta$ & $P$-value & Empirical evidence \\
\hline $\begin{array}{l}\mathbf{H}_{1}: \quad \text { there is a direct } \\
\text { relationship between spirituality } \\
\text { and counselling attitudes. }\end{array}$ & SP-----------> CA & 0.212 & 0.002 & Supported \\
\hline
\end{tabular}

\section{Discussion}

Based on the two central words, loneliness and satisfaction, spirituality brings companionship to the person and community. Furthermore, self-spirituality brings inner healing and sense of inner peace and accelerates the aspect of selfesteem. It also brings good health, strength and courage to everyday ordinary disappointments and pains. Disappointments created by factors assessed herein hampers spirituality and annihilates hope and a sense of togetherness.

The Guidance Counsellor often provides the client with a turning point for them to escape their struggles and problems. This becomes possible with their provision of spiritual insights of the ways applicable for managing common problems affecting the lives and wellbeing of their clients. Life is a continuous process where youth is engaged and exposed to failures and prosperity. Human beings are made to live in challenging conditions. Self-spirituality provides people with a ground of learning and teaches people on the healthy freedom of reacting positively.

Additionally, Souza (2002) argues that the realization through the application of spiritual assessment patterns, conditions an individual through a process of identifying ego and aspects of control of life. As such, it enables the youths to understand different personality aspects that affect their lives and life outcomes alongside their decision-making. This approach comes in line with the realization that human beings are not all rounded figures (perfect) and through this approach, one will notice that human beings are part of a larger process instituted by God. With the presence of one sovereign God in the physical world, there is a rapid growth in self-spirituality emphasized through different spiritual exercises and teachings. Concerns of these teachings focus on the youth behavior in relation to depression, anxiety, physical and sexual abuse.

In respect to this, Guidance Counsellors provide vast information in relation to spirituality and religion. Turner (2006) argues that the traditional role of the spiritual caregivers is to provide the youth with experiences ranging from inspiring, uplifting and assessment of traumatic and abusive attitudes. The goal is to acknowledge good and bad experiences that youth are forced to undergo.

Self-spirituality is thoughtful with careful preparation and sensitivity to the individual client. From this assessment, spirituality if incorporated provides a proper sensitive and respectful scheme that enrolls positive change through therapy. In fact, Sink (2008) argues that spiritual disciplines incorporate insights and skills about personality development in relation to the family.

Spiritual direction .provides an experience at which the youth is oriented to peaceful societies. The family further provides solutions at which issues are apprehended. For this reason, the family members and Guidance Counsellor is entitled to focus and respond carefully through a listening and close self-examination confession. Also, the Counsellor enrolls selfexamination and confession with a view to installing humility and promotes moral reform, revision of life and selfknowledge. Equally, he or she provides training in spiritual disciplines like meditation, prayer, and ascetic practices. Furthermore, religious practices such as fasting seek to present opportunities for overcoming spiritual problems. In summary, the tasks enrolled provide an expected operation framework, which acts as a critical reference point.

\section{Recommendations}

Changing from the lonely altitude to a positive counselling attitude remains an integral concern of the enrolment of a desirable family spiritual care. Guidance Counsellors are expected to adopt a plethora of factors, which specify a proper consent that is applicable to all youths. Secondly, he or she may incorporate others aspects relating to religious concern. The consent of spiritual dialogue with the youth provides a clear framework that attempts to prevent ethical dilemmas that arise as this incorporates dimensions of counseling. The Guidance Counsellor is mandated to collect suggestions based on spiritual and religious area, and this include: firstly, open discussion with the youth concerning his or her plight in 
relation to the spiritual realm. Secondly, the Counsellor should assess disturbed client preference of secular and religious paradigm.

Jankowski (2008) argues that this spiritual counseling is coherent with religious expectations since it enables the development of strategies that are primarily responsible in scheduling sessions of communicating between individuals in the society. Fellowships are in this case, placed to enhance the development of views and concerns. This approach is joined by Meier (2005) who examines that there is a need to enhance close examination of the inner soul.

In summary, Counselling and psychotherapy plays an important role in bringing about positive attitudes among youths through self-spirituality. The increase in cases of suicide among our youths could be attributed to drug abuse and frustration in life. Both the Guidance Counsellors and parents need to educate the youths that suicide is not the solution to their problems. Committing suicide is not only contrary to the laws of the land, but also against most religions. However, further analysis into the issues related to self-spirituality and its implications for positive counselling attitudes in the society among adults should also be conducted to identify the variables that influence the outcomes of the spiritual counseling.

\section{REFERENCES}

1. Azimi, H., Krauss, S.E., Sidek, M.N., Turiman, S., Rumaya, J., Jamiah, M... (2007). Muslim religiosity and personality assessment: Prototype for nation building. Serdang: Instittut Pengajian Sains Social.

2. Briggs, M. K., \& Dixon, A. L. (2013). Women's Spirituality across the Life Span: Implications for Counseling. Counseling and Values, 58(1), 104-120

3. Ciarrocchi, J. W. (2002). Counseling problem gamblers a self-regulation manual for individual and family therapy. San Diego: Academic Press

4. Craigie, F., \& Hobbs, R. (1999). Spiritual perspectives and practices of family physicians with an expressed interest in spirituality. Family medicine-kansas city-, 31, 578-585.

5. Fischer, E. H., \& Farina, A. (1995). Attitudes toward seeking professional psychological help: A shortened form and considerations for research. Journal of College Student Development, 36(4), 368-373.

6. Fischer, E. H., \& Turner, J. I. (1970). Orientations to seeking professional help: development and research utility of an attitude scale. Journal of consulting and clinical psychology, 35(1), 79

7. Frame, M. W. (2003). Integrating religion and spirituality into counseling: a comprehensive approach. Pacific Grove, CA: Thomson/Brooks-Cole

8. Gockel, A. (2004). The trend toward spirituality in the workplace: overview and implications for career counseling. Journal of Employment Counseling, 41(4), 156-167.

9. Gold, J. M. (2010). Counseling and spirituality: integrating spiritual and clinical orientations. Upper Saddle River, N.J.: Prentice Hall

10. Ironson, G., Solomon, G. F., Balbin, E. G., O'Cleirigh, C., George, A., Kumar, M. \& Woods, T. E. (2002). The Ironson-Woods Spirituality/Religiousness Index is associated with long survival, health behaviors, less distress, and low cortisol in people with HIV/AIDS. Annals of Behavioral Medicine, 24(1), 34-48.

11. Jankowski, P. J., \& Vaughn, M. (2009). Differentiation of Self and Spirituality: Empirical Explorations. Counseling and Values, 53(2), 82-96

12. Koenig, H., Parkerson Jr, G. R., \& Meador, K. G. (1997). Religion index for psychiatric research.

13. Kvarfordt, C. L. (2009). Explorations in Counseling and Spirituality: Philosophical, Practical, and Personal Reflections. Journal of Religion \& Spirituality in Social Work: Social Thought, 28(3), 339-340

14. Ling, L. (Director). (2006). World's most dangerous drug [Documentary]. United States: Warner Home Video

15. Meier, A. (2005). Spirituality and health multidisciplinary explorations. Waterloo, Ont.: Wilfred Laurie University Press

16. Romero, C., Friedman, L. C., Kalidas, M., Elledge, R., Chang, J., \& Liscum, K. R. (2006). Self-forgiveness, spirituality, and psychological adjustment in women with breast cancer. Journal of Behavioral Medicine, 29(1), 29-36.

17. Salsman, J. M., Brown, T. L., Brechting, E. H., \& Carlson, C. R. (2005). The link between religion and spirituality and psychological adjustment: The mediating role of optimism and social support. Personality and social psychology bulletin, 31(4), 522-535.

18. Sandoz, J. (2006). Neuro-Spirituality. American Journal of Pastoral Counseling, 8(2), 55-71.

19. Sink, C. A. (2008). Wisdom of Robert Solomon: Naturalized Spirituality and Counseling. Counseling and Values, 52(3), 178-180

20. Souza, K. Z. (2002). Spirituality in Counseling: What Do Counseling Students Think About It? Counseling and Values, 46(3), 213-217 
21. Taylor, R. J., Chatters, L. M., \& Jackson, J. S. (2007). Religious and spiritual involvement among older African Americans, Caribbean blacks, and non-Hispanic whites: Findings from the national survey of American life. The Journals of Gerontology Series B: Psychological Sciences and Social Sciences, 62(4), 238-250.

22. Turner, T. E. (2006). Uniting Spirituality and Sexual Counseling: Eastern Influences. The Family Journal, 14(1), 81-84

23. Wolf, C. T., \& Stevens, P. (2001). Integrating Religion and Spirituality in Marriage and Family Counseling. Counseling and Values, 46(1), 66-75.

24. Woods, T. E., \& Ironson, G. H. (1999). Religion and spirituality in the face of illness how cancer, cardiac, and hiv patients describe their spirituality/religiosity. Journal of Health Psychology, 4(3), 393-412.

\section{Author' biography with Photo}

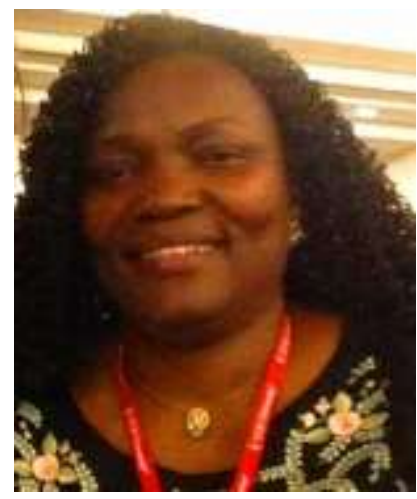

Grace Tanimoonwo Idowu (nee Fasugba MeLord) is a trained teacher with a Master's degree (M.Ed.'87) in Guidance and Counselling. A motivator and a goal-getter with a focus, who enrolled for the Ph.D. Program 25 years after obtaining the Master's degree. She is currently in the field of Counseling Psychology as a Ph.D. candidate, specializing in Family Therapy and Counselling Attitudes at the Universiti Putra Malaysia. She is a member of International Family Therapy Association and Nigerian Counselling Association. 